\title{
The Wide Range of Antibiotic Resistance and Variability of Genotypic Profiles in Escherichia coli from Domestic Animals in Eastern Sicily
}

\author{
Nunziatina Russo ${ }^{1,+}$, Alessandro Stamilla ${ }^{1,+}+{ }^{+}$, Giuseppe Cascone ${ }^{2}$, Cinzia Lucia Randazzo ${ }^{1}$, \\ Antonino Messina ${ }^{3}{ }^{-}$, Massimiliano Lanza ${ }^{1}$, Alessandra Pino ${ }^{1}{ }^{\mathbb{D}}$, Cinzia Caggia ${ }^{1, *}$ and Francesco Antoci ${ }^{2}$ \\ 1 Dipartimento di Agricoltura, Alimentazione e Ambiente (Di3A), University of Catania, 95124 Catania, Italy; \\ nunziatinarusso83@gmail.com (N.R.); alessandrostamilla@gmail.com (A.S.); cinzia.randazzo@unict.it (C.L.R.); \\ malanza@unict.it (M.L.); alessandra.pino@unict.it (A.P.) \\ 2 Istituto Zooprofilattico Sperimentale of Sicily, 90129 Palermo, Italy; giuseppe.cascone@izssicilia.it (G.C.); \\ antocif@gmail.com (F.A.) \\ 3 DVM Consultant Poultry Specialists, via Cava Gucciardo Pirato, 12, 97015 Modica, Italy; \\ vetmessina@gmail.com \\ * Correspondence: cinzia.caggia@unict.it; Tel.: +39-095-7580218 \\ + These authors contributed equally.
}

\section{check for}

updates

Citation: Russo, N.; Stamilla, A.; Cascone, G.; Randazzo, C.L.; Messina, A.; Lanza, M.; Pino, A. Caggia, C.; Antoci, F. The Wide Range of Antibiotic Resistance and Variability of Genotypic Profiles in Escherichia coli from Domestic Animals in Eastern Sicily. Antibiotics 2021, 10, 28 https://doi.org/10.3390/ antibiotics10010028

Received: 20 November 2020 Accepted: 29 December 2020 Published: 31 December 2020

Publisher's Note: MDPI stays neutral with regard to jurisdictional clai$\mathrm{ms}$ in published maps and institutional affiliations.

Copyright: (C) 2020 by the authors. Licensee MDPI, Basel, Switzerland. This article is an open access article distributed under the terms and conditions of the Creative Commons Attribution (CC BY) license (https:// creativecommons.org/licenses/by/ $4.0 /)$.

\begin{abstract}
The emergence of multidrug resistance among Enterobacteriaceae in livestock poses a serious public health threat. Escherichia coli, a usual host of intestinal microbiota, is recognized also as etiological agent of numerous infections widespread in both humans and animals. The colibacillosis is one of the most reported zoonoses worldwide, typically treated with antibiotics in the primary stages. This strategy has promoted the onset of antibiotic-resistant serotypes of $E$. coli, reducing the effectiveness of therapeutic treatments and contributing to antibiotic resistance spread. The current study focused on biodiversity, pathogenicity, and antibiotic resistance profile of $104 \mathrm{E}$. coli strains isolated from domestic animals in Eastern Sicily. The strains were isolated from sick animals and carcasses of six different animal species and screened for resistance against 16 antibiotic molecules, as recommended by WHO and OIE. The antibiotic resistance patterns highlighted that all strains were multi-resistant, showing resistance to at least three antibiotic classes. The highest incidence of resistance was observed against amoxicillin $(100 \%)$, tylosin $(97 \%)$, sulfamethoxazole $(98 \%)$, and erythromycin $(92 \%)$, while the lowest for colistin $(8 \%)$. The pathotype characterization identified two EPEC strains and the study of genetic linkage (PFGE) showed a wide variety of profiles. The current study emphasized the wide range of multidrug resistance and genotyping profiles in E. coli isolated in Easter Sicily.
\end{abstract}

Keywords: Escherichia coli; antimicrobials; multidrug resistance; colistin; PFGE profile; veterinary

\section{Introduction}

Escherichia coli, a gram-negative, non-sporulating, facultative anaerobic bacteria, is a natural part of human and warm-blooded animal microbiota, harbored in the colon as a component of the commensal population, living in a symbiotic relationship with the host [1]. Although E. coli represents only around 1\% of the intestinal microbiota [2], it shows the highest ability to survive, and even grow, outside the host [3-5]. This ability is associated with a high phenotypic diversity, mirrored by the high genomic plasticity of E. coli, confirmed by the acquisition of numerous mobile genetic elements [6]. Among bacteria, $E$. coli possesses the most diverse lifestyles, and the species includes both commensal and highly pathogenic strains. These latter can cause a wide variety of intestinal and extra-intestinal infections, and some specific serotypes are associated with certain clinical syndromes, and thus serotypes serve as readily identifiable markers that correlate with specific virulent clones [7]. Evolution of E. coli is caused by both vertical and horizontal gene 
transfer. Variable genes, such as plasmids, prophages, and pathogenicity islands (PAIs) [8] make up more than two thirds of the E. coli genome. Of major concern is the transmission of virulent and/or resistant $E$. coli between animals and humans through numerous pathways, such as direct contact, contact with animal excretions, or via the food chain. E. coli also represents a major reservoir of resistance genes that may be responsible for treatment failures in both human and veterinary medicine. Among animal species, the infection by different E. coli strains is widespread and sometimes fatal [9]. One of the most frequently reported diseases worldwide is colibacillosis and, in 2017, Shiga Toxin/Verocytotoxin producing E. coli infection has been reported as the fourth most common zoonosis in the EU [10]. Colibacillosis is an extra-intestinal disease characterized by pericarditis, air sacculitis, perihepatitis, peritonitis, that represents a problem of significant economic importance, causing relevant livestock loss [11-13]. As known, especially in rural farms, two main pathotypes involved in enteric colibacillosis are the entero-toxigenic E. coli (ETEC) and the entero-pathogenic E. coli (EPEC) $[13,14]$. Antimicrobials are the main weapon to fight both the incidence and the mortality associated with colibacillosis [15]. However, typical treatment strategies and, in particular, administration of antibiotics in the primary stages of the disease, have promoted the onset of antibiotic-resistant serotypes of $E$. coli, leading to a reduction in the effectiveness of therapeutic treatments against colibacillosis. In general, the emergence of antibiotic resistance has been documented in E. coli isolated from human, animal and environmental sources and represents an emerging health concern [16-18]. The selective pressure of antimicrobial use, overuse and misuse in humans and animals comprises the engine driving this process leading to a gradual increase in antibiotic resistance [19]. Consequently, diseases that in the past were treatable are now untreatable or require the latest line of antibiotics [20]. Moreover, the food animal industry contributes to the increasing occurrence of AR through certain farm management practices to promote the well-being and growth of animals that can promote the selection of resistomes in the environment, with potential spillover to animals and humans [21-24].

Recent surveillance data from the 2000s indicate that, within E. coli species, a high antibiotic resistance profile to the major antibiotic classes has been detected [21]. Epidemiological studies in farms are important to provide information about the risk factor for the emergence and persistence of antimicrobial resistance, representing a useful tool to explain the co-selection and the cross-resistance from various antimicrobials and their persistence in the absence of direct selection pressure $[25,26]$. Indeed, E. coli has acquired resistance to cephalosporins, carbapenems, aminoglycosides, fluoroquinolones, and polymyxins. In addition, strains of animal origin often show resistances to other antimicrobial agents, including tetracyclines, phenicol, sulfonamides, trimethoprim, and fosfomycin, and the ability to acquire resistance to colistin, tetracyclines, phenicol, sulfonamides, trimethoprim, and fosfomycin. Molecular characterization of resistant isolates by fingerprinting techniques is an important tool to describe the spread of bacterial clonal units. Among fingerprinting techniques, the pulsed-field gel electrophoresis (PFGE) is particularly useful to demonstrate close relationships among strains, including those manifesting multidrug resistance [18].

The aim of the present study was to evaluate the prevalence of antibiotic resistance of E. coli strains isolated from different animal species, presumptively affected by colibacillosis, in order to assess their impact on animal health and food safety. For this purpose, the biodiversity, the pathogenicity and the antibiotic resistance profile of strains isolated from multiple tissue sites of domestic animals were tested.

\section{Results}

\subsection{Antimicrobial Resistance}

Based on EUCAST and CLSI criteria [27,28], all tested strains showed multi-drug resistance against most common veterinary prescribed antibiotics. In detail, in Table 1, the antibiotic resistance profiles of tested strains were reported. Overall, all tested strains showed resistance against at least three antibiotic-classes, resulting in multi-resistance 
(a comprehensive description of the strain and antibiotic resistance profiles is provided in Supplementary Materials, Table S1).

Table 1. Antibiotic-resistance pattern of E. coli population.

\begin{tabular}{cccccccc}
\hline \multirow{2}{*}{$\begin{array}{c}\text { Antimicrobial } \\
\text { Agents }\end{array}$} & No. Tested & \multicolumn{2}{c}{ Resistant } & \multicolumn{2}{c}{ Intermedium } & \multicolumn{2}{c}{ Susceptible } \\
\cline { 3 - 7 } & & no. & \% & no. & \% & no. & \% \\
\hline Aminosidine & 104 & 30 & 29 & 1 & 1 & 73 & 70 \\
Colistin 1 & 104 & 8 & 8 & 0 & 0 & 96 & 92 \\
Enrofloxacin & 104 & 48 & 46 & 10 & 10 & 46 & 44 \\
Lincomycin and & 104 & 34 & 33 & 22 & 21 & 48 & 46 \\
Spectomicin & 104 & 71 & 68 & 20 & 19 & 13 & 13 \\
Oxytetracycline & 104 & 52 & 50 & 42 & 40 & 10 & 10 \\
Thiamphenicol & 104 & 52 & 50 & 1 & 1 & 51 & 49 \\
Tylmicosin & 104 & 101 & 97 & 1 & 1 & 2 & 2 \\
Tylosin & 104 & 58 & 56 & 2 & 2 & 44 & 42 \\
Trimethoprim & 104 & 98 & 94 & 6 & 6 & 0 & 0 \\
Sulphamethoxazole & 104 & 78 & 75 & 8 & 8 & 18 & 17 \\
Ampicillin & 104 & 68 & 65 & 18 & 17 & 18 & 17 \\
Doxycycline & 104 & 56 & 54 & 8 & 8 & 40 & 38 \\
Flumequine & 104 & 96 & 92 & 7 & 7 & 1 & 1 \\
Erythromycin & 104 & 104 & 100 & 0 & 0 & 0 & 0 \\
Amoxicillin & 104 & 33 & 32 & 1 & 1 & 70 & 67 \\
Apramycin & 104 &
\end{tabular}

${ }^{1}$ Minimum Inhibitory Concentration (MIC) was determined by the micro-broth dilution method using the MIC-strip kit (MERLIN Diagnostika GmbH, Bornheim, Germany).

The antibiotic resistance patterns highlighted that three out $104(2.9 \%)$ strains showed resistance against 15 among the 16 tested antibiotics. The most of tested strains, 17 out $104(16.3 \%)$, showed resistance to nine antibiotics, 11 strains $(10.6 \%)$ showed resistance to 10 molecules, 10 strains (9.6\%) against 12 molecules and other 10 strains against eight molecules. Zooming on the resistance distribution, the highest incidence was observed against amoxicillin $(100 \%)$, tylosin $(97 \%)$, sulphamethoxazole $(94 \%)$, and erythromycin $(92 \%)$, whereas lower incidences were observed for aminoglycosidic antibiotics, with the $29 \%$ and $32 \%$ of strains resistant against aminosidine and apramycin, respectively (Table 1 ).

To investigate the differences of E. coli strains isolated from bovine and poultry animals, based on antibiotic resistance profiles, principal component analysis (PCA) was employed. Score plot is effective in showing the difference among resistance profile of $E$. coli strains and in separating them in the graph. Overall, three main groups (A, B and C) were detected (Figure 1). In detail, closer distances were detected among both bovine and poultry isolates, clustered into the group A, that includes strains with the highest level of resistance. On the contrary, into the group B, clustering strains with higher level of susceptibility, a great dispersion for strains from bovine was observed. Although less closely spaced, the strains EC92, EC105, and EC 113, that exhibited susceptibility to aminosidine, colistin, lincomycin and spectomicin, tylmicosin, trimethoprim and apramycin, and categorized as intermediate for sulphamethoxazole, were grouped into group C. Finally, the strains EC114 and EC103, positioned far away from other groups, were distinguished to show resistance to antibiotics different to those listed in the opposite quarter (Figure 1). 


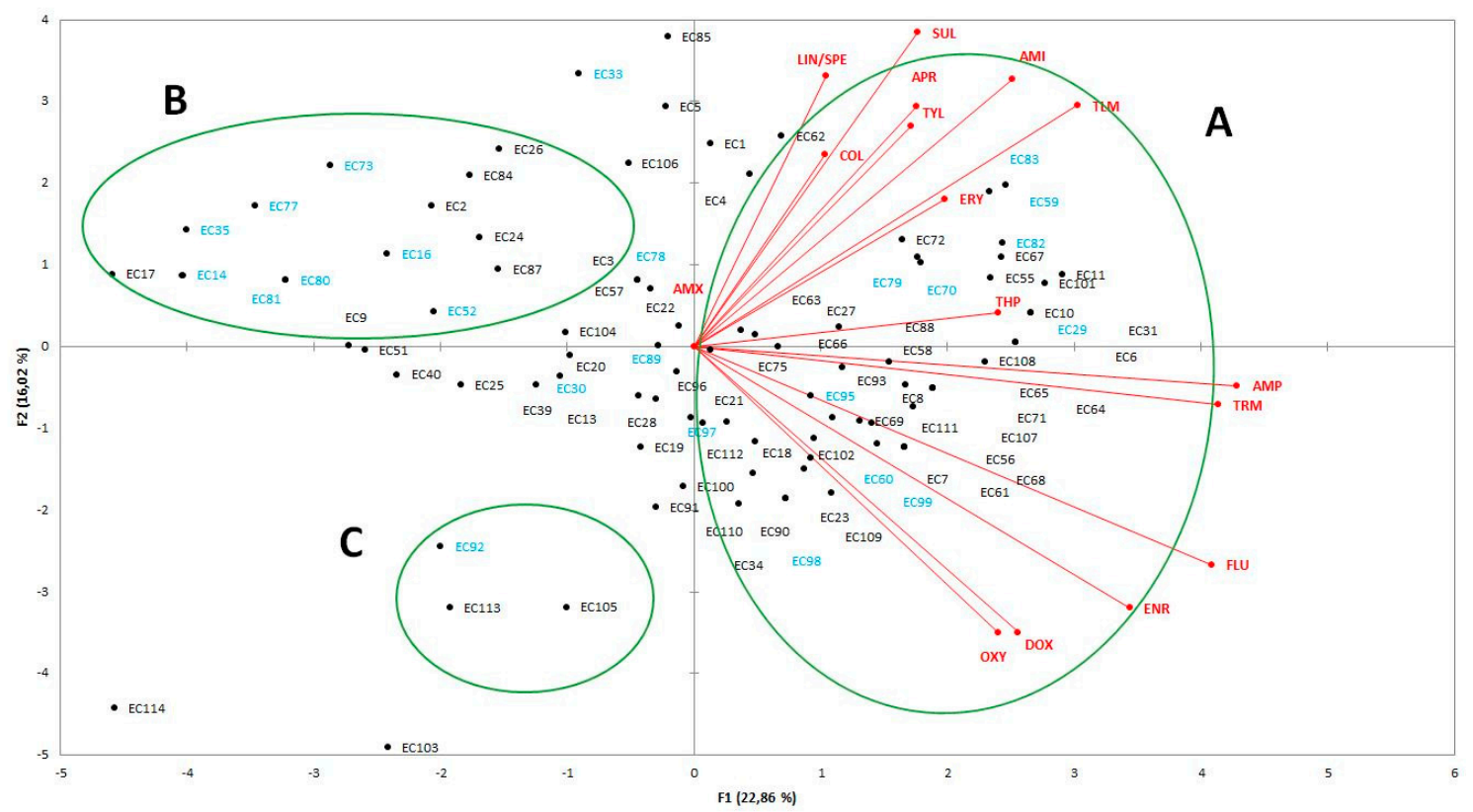

Figure 1. Biplot of principal component analysis (PCA) analysis showing the antibiotic resistance distribution among E. coli strains isolated from bovine (in blue) and poultry (in black).

Although the lowest incidence (8\%) of resistance was observed to colistin, the eight resistant strains showed a MIC value of $16 \mu \mathrm{g} / \mathrm{mL}$ (data not shown), which is much higher than the clinical breakpoint [23]. Furthermore, the colistin-resistant strains, despite isolated from different domestic animals, were distinguished for the high level of resistance, spanning from 15 to 8 antibiotics (Table 2). Focusing on the single antibiotic patterns, all the eight colistin-resistant E. coli strains (EC11, EC23, EC33, EC36, EC59, EC62, EC83, EC85) showed concurrent resistance to tylosin, sulphamethoxazole, and amoxicillin. Among them, the EC23 strain showed sensibility to aminosidine, tylmicosin, and apramycin and the EC33 distinguished from others for the highest level of susceptibility and the highest level of intermediated categorization to thiamphenicol, ampicillin, doxycycline, and flumequine (Table 2). The antibiotic resistance profiles observed for the two EPEC strains showed a high degree of variability, with the EC15 strain exhibiting resistance to only three antibiotics (tylosin, sulphamethoxazole and amoxicillin) and the EC15 strain exhibiting susceptibility exclusively to colistin as well as lincomycin and spectomicin antibiotics and resistance against all other 14 tested antibiotics (Table 2). 
Table 2. Antibiotic resistance pattern of clostin-resistant and $\mathrm{EPEC}^{+}$E. coli strains.

\begin{tabular}{|c|c|c|c|c|c|c|c|c|c|c|}
\hline \multirow{2}{*}{$\begin{array}{c}\text { Antimicrobial } \\
\text { Agents }\end{array}$} & \multicolumn{8}{|c|}{ Colistin-Resistant Strains } & \multicolumn{2}{|c|}{ EPEC $^{+}$Strains } \\
\hline & EC11 & EC23 & EC33 & EC36 & EC59 & EC62 & EC83 & EC85 & EC15 & EC31 \\
\hline Aminosidine & $\mathrm{R}$ & $S$ & $\mathrm{R}$ & $\mathrm{R}$ & $\mathrm{R}$ & $\mathrm{R}$ & $\mathrm{R}$ & $\mathrm{R}$ & $S$ & $\mathrm{R}$ \\
\hline Colistin & $\mathrm{R}$ & $\mathrm{R}$ & $\mathrm{R}$ & $\mathrm{R}$ & $\mathrm{R}$ & $\mathrm{R}$ & $\mathrm{R}$ & $\mathrm{R}$ & S & $\mathrm{S}$ \\
\hline Enrofloxacin & $\mathrm{R}$ & $\mathrm{R}$ & $S$ & $\mathrm{R}$ & $S$ & $\mathrm{~S}$ & $\mathrm{R}$ & $S$ & $\mathrm{~S}$ & $\mathrm{R}$ \\
\hline $\begin{array}{l}\text { Lincomycin and } \\
\text { Spectomicin }\end{array}$ & $S$ & $S$ & $S$ & $\mathrm{R}$ & I & I & $\mathrm{R}$ & $\mathrm{R}$ & $S$ & $S$ \\
\hline Oxytetracycline & $\mathrm{R}$ & $\mathrm{R}$ & $S$ & $\mathrm{R}$ & $\mathrm{R}$ & $\mathrm{R}$ & $\mathrm{R}$ & I & $S$ & $\mathrm{R}$ \\
\hline Thiamphenicol & $\mathrm{R}$ & $\mathrm{R}$ & I & $\mathrm{I}$ & $\mathrm{R}$ & $\mathrm{R}$ & I & I & $S$ & $\mathrm{R}$ \\
\hline Tylmicosin & $\mathrm{R}$ & $S$ & $\mathrm{R}$ & I & $\mathrm{R}$ & $\mathrm{R}$ & $\mathrm{R}$ & $\mathrm{R}$ & $S$ & $\mathrm{R}$ \\
\hline Tylosin & $\mathrm{R}$ & $\mathrm{R}$ & $\mathrm{R}$ & $\mathrm{R}$ & $\mathrm{R}$ & $\mathrm{R}$ & $\mathrm{R}$ & $\mathrm{R}$ & $\mathrm{R}$ & $\mathrm{R}$ \\
\hline Trimethoprim & $\mathrm{R}$ & $\mathrm{R}$ & $S$ & $\mathrm{R}$ & $\mathrm{R}$ & $S$ & $\mathrm{R}$ & $S$ & $S$ & $\mathrm{R}$ \\
\hline Sulphamethoxazole & $\mathrm{R}$ & $\mathrm{R}$ & $\mathrm{R}$ & $\mathrm{R}$ & $\mathrm{R}$ & $\mathrm{R}$ & $\mathrm{R}$ & $\mathrm{R}$ & $\mathrm{R}$ & $\mathrm{R}$ \\
\hline Ampicillin & $\mathrm{R}$ & $\mathrm{R}$ & I & $\mathrm{R}$ & $\mathrm{R}$ & $\mathrm{R}$ & $\mathrm{R}$ & $\mathrm{R}$ & $S$ & $\mathrm{R}$ \\
\hline Doxycycline & $\mathrm{R}$ & $\mathrm{R}$ & I & $\mathrm{R}$ & $\mathrm{R}$ & $\mathrm{R}$ & $\mathrm{I}$ & $\mathrm{I}$ & I & $\mathrm{R}$ \\
\hline Flumequine & $\mathrm{R}$ & $\mathrm{R}$ & $\mathrm{I}$ & $\mathrm{R}$ & $\mathrm{R}$ & $S$ & $\mathrm{R}$ & $S$ & $S$ & $\mathrm{R}$ \\
\hline Erythromycin & $\mathrm{R}$ & $\mathrm{I}$ & $\mathrm{R}$ & $\mathrm{R}$ & $\mathrm{R}$ & $\mathrm{R}$ & $\mathrm{R}$ & $\mathrm{R}$ & I & $\mathrm{R}$ \\
\hline Amoxicillin & $\mathrm{R}$ & $\mathrm{R}$ & $\mathrm{R}$ & $\mathrm{R}$ & $\mathrm{R}$ & $\mathrm{R}$ & $\mathrm{R}$ & $\mathrm{R}$ & $\mathrm{R}$ & $\mathrm{R}$ \\
\hline Apramycin & $\mathrm{R}$ & $S$ & $\mathrm{R}$ & $\mathrm{R}$ & $\mathrm{R}$ & $\mathrm{R}$ & $\mathrm{R}$ & $\mathrm{R}$ & S & $\mathrm{R}$ \\
\hline
\end{tabular}

R: Resistant; I: Intermedium; S: Susceptible.

Interestingly, 42 out 104 strains (40\%) were grouped into the intermediate category for resistance to thiamphenicol, which could be interpreted as a launch into resistance acquisition.

\subsection{DEC Phatotypes Detection}

The multiplex PCR assay, applied in the present work for the rapid detection of specific categories of pathogenic types, revealed that none of the tested strains showed the tested genes for EAEC, STEC, ETEC, and EIEC pathotypes. Only two strains, the EC15 and the EC31, isolated from dog breast and broiler liver, respectively, were found harboring the eae gene (EPEC pathotype).

\subsection{PFGE Analysis}

PFGE was performed in order to study the genetic linkage among E. coli strains isolated from different domestic animals. Data showed that the XbaI digestion allowed obtaining a range, spanning from 7 to 21, visibly distinguishable fragments (Figure 2). Indeed, in the present study, the technique allowed to cluster 70 out of 104 of E. coli tested strains. The analysis of dendrogram showed a wide variety of profiles, with any correlation between a specific profile and a defined animal species, isolation site, or year of isolation. As previously reported, these data suggest a great variety among $E$. coli strains shed in the domestic animals setting and into the environment in general [18,29]. 


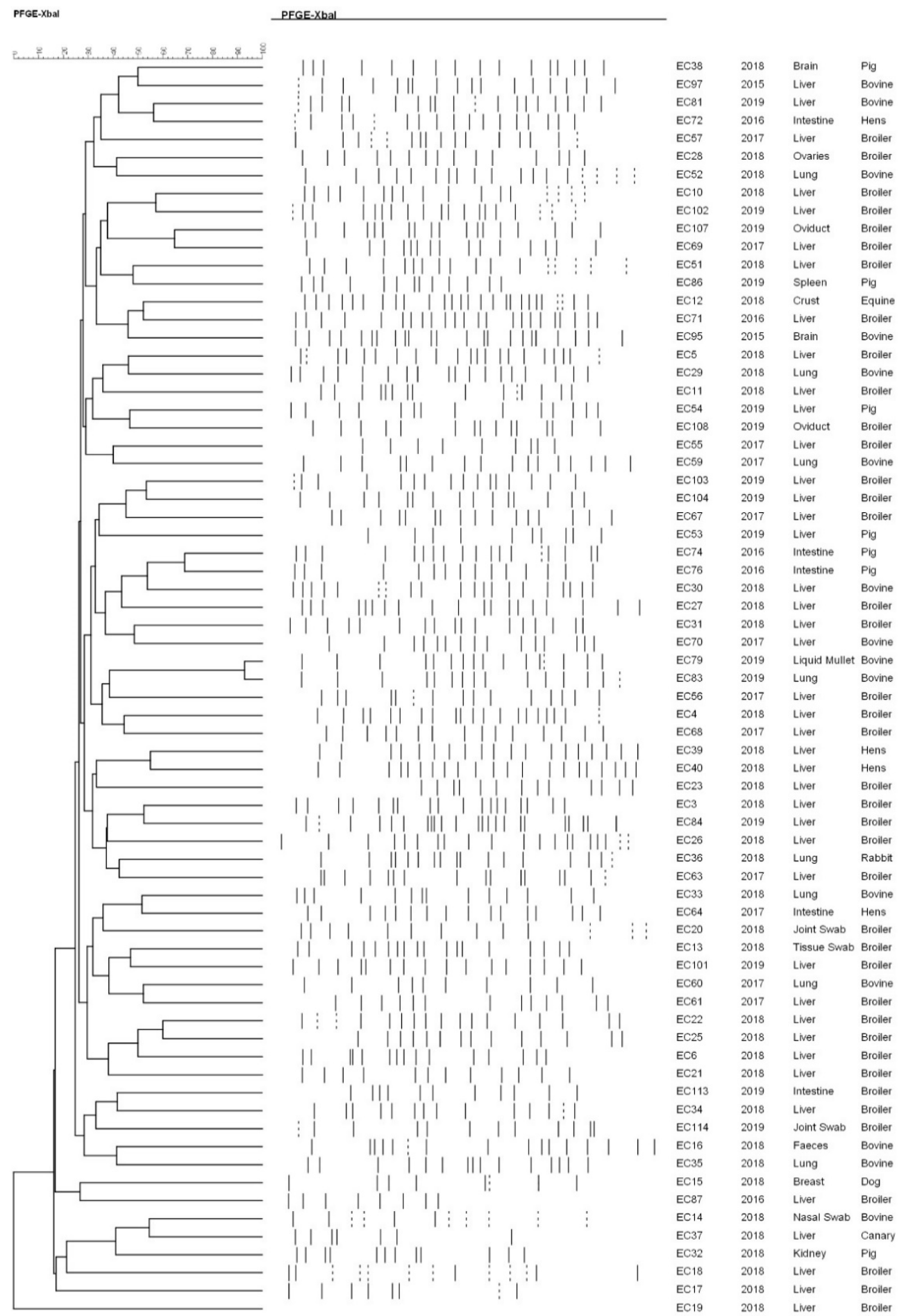

Figure 2. Escherichia coli phylogenetic three based on pulsed-field gel electrophoresis (PFGE) analysis.

\section{Discussion}

It is well known that E. coli, although a normal inhabitant of the intestinal tract, can also be associated with a variety of pathological conditions in both humans and farm animals [30]. Moreover, the largest resistance to numerous antimicrobial agents of interest of both human and veterinary fields observed in E. coli strains represents a serious problem to global public health, resulting in a significant impact on animal health and food safety [31]. Colibacillosis, an extra-intestinal disease caused by ETEC and EPEC E. coli pathotypes, represents one of the most frequently reported disease worldwide in the 
livestock farm, commonly countered by antibiotics [11-13] and thus a further worrying source of spread of antibiotic resistance.

The present investigation was conducted to achieve phenotypic resistance profile against the commonly veterinary prescribed antibiotics in clinical strains, isolated from different domestic animals, probably affected by colibacillosis. Results of DEC detection, through multiplex PCR analysis, showed that the majority of the strains did not show the presence of the intimin adhesin encoded by the eae gene from the LEE (locus of enterocyte effacement) pathogenicity island, with the exception of two strains. The implications of the presence of pathogenic and/or commensal strains in the intestinal environment are not clearly discernible, although it can be speculated that this could be a leading source of a diverse range of EPEC strains, as reported for atypical enterohaemorrhagic and enteropathogenic E. coli $[32,33]$. However, the diversity within both E. coli sero-groups and sero-types is commonly reported [34], confirming the heterogeneous nature of EPEC in terms of virulence features. Indeed, well-recognized virulence factors do not occur universally among EPEC, suggesting the presence of multiple alternative mechanisms mediating pathogenicity. Finally, in addition to the virulence status of the strain, host status and presence and type of predisposing factors must be considered for their influence in the infection symptoms and severity [32].

In the present study, all strains showed multi-resistance, being resistant against at least three antibiotic classes. Our findings are in agreement with previous reports highlighting the emergence, propagation, accumulation, and maintenance of antimicrobial-resistant pathogenic E. coli in human and veterinary medicine [35-38]. The phenotypic antibiotic resistance patterns showed high resistance to the most common veterinary antibiotics such as amoxicillin, tylosin, sulfamethoxazole, and erythromycin. The high degree of observed resistance could be explained by the fact that many antimicrobials are used to treat domestic animal infections, and in the past, as growth promoters or preventative measures $[18,39,40]$. Such a high level of resistance to amoxicillin is probably related to the popularity of the $\beta$-lactams, in both human and animal disease treatments [39]. Moreover, in E. coli species, one of the most remarkable phenomena is the rapid increase of plasmid-mediated beta-lactam resistance, which contributes to a faster diffusion of resistance in different environments $[41,42]$. The routine exposure, for extended periods, to sub-therapeutic doses of antimicrobial agents by livestock species contributes to a significantly higher prevalence of resistance, compared to species that are typically exposed to therapeutic doses for brief periods $[39,43]$. Likewise, the approved use of tylosin in feed, as a preventive measure for liver abscess, has probably contributed to the relative resistance increase [41,42].

Regarding the high incidence of erythromycin- and sulphamethoxazole-resistance, the results of the present study are in agreement with those recently reported [44] on E. coli isolated from different sources. Although several reports on E. coli highlighted a wide distribution of colistin resistance, frequently mediated by the mobile mor gene [44], in the present study, the percentage of resistance against colistin was low. This finding is great of interest because colistin is recognized as the last-resort antibiotic for the treatment of infectious diseases caused by multidrug-resistant (MDR) gram-negative bacteria [44]. Moreover, as recommended by the EUCAST subcommittee [45], in the present study the resistance to colistin was confirmed by determination of MIC through broth micro-dilution method. According to the EUCAST [46] and Loose et al. [47], a strain is defined as colistinresistant (for $m c r-1$ gene presence) when the MIC value ranged between $4.0-16 \mathrm{mg} / \mathrm{L}$ and colistin-susceptible (commonly for the non-mor-1 presence) when the MIC values ranged between $0.25-1.0 \mathrm{mg} / \mathrm{L}$. Hence, the MIC value of $16 \mathrm{mg} / \mathrm{L}$, revealed in the present study, can be attributed to the presence of plasmid-transferred mobilized colistin resistance mcr-1 gene [48-50]. Moreover, the colistin resistance was always related to resistance to tylosin, sulphamethoxazole, and amoxicillin, as recently reported [44].

Furthermore, the intermediated categorization obtained for thiamphenicol antibiotics (chloramphenicol representative derivative), synonym of observed reduced susceptibility, suggests the possibility of acquiring resistance [51]. Amphenicols present a broad-spectrum 
inhibitory effect on both gram-positive and -negative bacteria but are particularly effective against the latter. The severe levels of resistance to amphiphenicles may be attributable to spread or abuse in the animal industry, which may have increased selective pressure on E. coli [52]. The antibiotic resistance profiles observed for the two EPEC strains showed high variability, confirming the importance of the considerable polymorphism of genes encoding for this virulence factor. Likewise, the acquisition and the exchange of the virulence gene among pathogenic $E$. coli strains are believed to provide an evolutionary pathway to pathogenicity [53]. Moreover, no correlation was observed between phenotypic antibiotic resistance and reference animal and/or isolation site, or year of isolation.

Finally, the clonal relationship among strains by XbaI-PFGE was explored. Macro-restriction analysis by PFGE is capable of clustering and differentiating many pathogens due to its sensitivity and discriminatory power. Although both traits might be affected by the organism and the used restriction enzyme, PFGE has a high epidemiologic relevance and is the "gold standard" method for subtyping bacterial pathogens [54] Typing methods for discriminating different bacterial isolates of the same species are an essential epidemiological tool in infection prevention and control. However, although PFGE is considered as the "gold standard", many strains are not typable by this technique due to the degradation of the DNA during the process (gel smears) [29,33]. In the current study, the observed high genetic diversity, highlighted by the unique pattern pulso-types, confirms the independent origin of the strains, being genetically distinct from one another. This fact might be explained by the large genomic diversity of $E$. coli isolates, also confirmed by applying multi-locus enzyme electrophoresis technique $[55,56]$. Our results showed no correlation with any PFGE patterns within the same animal sample, tissue site or among the same geographical location, or on the year of isolation. These results were predictable because, as previously reported, the different isolation sources involved genetic differences of strains [57]. Moreover, no correlation was observed between the antibiotic resistance patterns and PFGE types. The possibility of horizontal transfer of mobile genetic elements to confer resistance, such as plasmids, integrons, or phage-mediated exchange, could likely contribute to different PFGE patterns, as observed here [58].

The present study, offering a snapshot of antibiotic the resistance profile of $E$. coli strains commonly isolated from livestock farms, underscores the need for a clear assessment of drug resistance of E. coli as a normal inhabitant of the intestinal tract. Indeed, numerically dominant commensals and not frank pathogens, represent the dominant lineages here observed. Further studies (e.g., surveillance) are indicated to identify the role of nonpathogenic E. coli strains and risk factors associated with antibiotic resistance spread.

\section{Materials and Methods}

\subsection{Source of E. coli Isolation}

In the present work, a total of 104 E. coli strains were tested. In detail, the strains were previously isolated and identified at the Istituto Zooprofilattico Sperimentale of Sicily, in Ragusa, from June 2015 to December 2019. The strains were isolated from necroscopies of various domestic animals, $(n=68)$ poultry, $(n=24)$ bovine, $(n=7)$ swine, $(n=1)$ buffalo, $(n=1)$ canine, $(n=1)$ canary, $(n=1)$ equine, $(n=1)$ rabbit that died due to colibacillosis or showed symptoms connected with E. coli infection or the onset of concomitant diseases. In detail, a total of 102 swabs were analyzed, 96 from of organs and six from breast swabs (from canine, equine, and bovine), one from bovine cephalorachidian fluid and two from bovine and equine crusts. The organs were aseptically withdrawn, placed in cabin, burned in the surface, and cut longitudinally with scalpel approximately $3 \mathrm{~cm}$. The internal fluid samples were picked up via swab inserted inside the trimmed area. The swab of each sample was streaked onto a MacConkey's agar plate and incubated a $37^{\circ} \mathrm{C}$ for $24 \mathrm{~h}$. Suspected E. coli colonies were re-plated onto blood agar in duplicate. The colonies were identified using two different methods: The API ${ }^{\circledR} 20 \mathrm{E}$ (Biomerieux, Nouveautès, France) and the GN card with VITEK ${ }^{\circledR} 2$ (Biomerieux, France) tests. Analyses were performed according to the manufacturer's instructions, using the specific software: ApiwebTM and 
VITEK 2 Systems, version 08.02 . The E. coli isolates were stored at $-80^{\circ} \mathrm{C}$ in CRYOBANK ${ }^{\circledR}$ (Mast Group, Bootle, UK) until the use.

\subsection{Susceptibility Test}

The 104 E. coli strains were tested for antibiotic susceptibility against 16 antimicrobial agents, using disk agar diffusion method, according to the Clinical Laboratory Standard Institute (CLSI) [28] and EUCAST guidelines [27]. Antibiotics were selected based on the recommendations of the World Health Organization (WHO) and World Organization for Animal Health. The tested antibiotics belonged to 11 classes of antimicrobial agents were: Aminosidine (AMI, $60 \mu \mathrm{g}$ ), Colistin (COL, $10 \mu \mathrm{g}$ ), Enrofloxacin (ENR, $5 \mu \mathrm{g}$ ), Lincomycin/Spectinomycin (LIN/SPE $2+100 \mu \mathrm{g}$ ), Oxytetracycline (OXY, $30 \mu \mathrm{g})$, Thiamphenicol (THP, $30 \mu \mathrm{g}$ ), Tilmicosin (TLM, $15 \mu \mathrm{g}$ ), Tylosin (TYL, $30 \mu \mathrm{g}$ ), Trimethoprim (TRM, $1.5 \mu \mathrm{g}$ ), Sulphamethoxazole (SUL, $25 \mu \mathrm{g}$ ), Ampicillin (AMP, $10 \mu \mathrm{g}$ ), Doxycycline (DOX, $30 \mu \mathrm{g}$ ), Flumequine (FLU, $30 \mu \mathrm{g}$ ), Erythromycin (ERY, $15 \mu \mathrm{g}$ ), Amoxicillin (AMX, $25 \mu \mathrm{g}$ ) and Apramycin (APR, $30 \mu \mathrm{g})$. For the colistin-resistant strains, the minimum inhibition concentrations (MIC) were determined by broth microdilution method, using the MIC-Strip Colistin (MERLIN Diagnostika GmbH, Bornheim, Germany), according to the manufacturer's instructions, following the International Standard reference method (ISO 20776-1) [59], as recommended by the EUCAST subcommittee [45].

\subsection{DEC Pathotypes Investigation}

The pathogenicity of individual E. coli lineages is mostly related to virulence gene content [29]. For this reason, the screening for specific virulence genes, defining the five most relevant DEC pathotypes, was performed in the present study. As reported by Ori et al. (2018) [34], a multiplex PCR assay was carried out for the EPEC, EAEC, STEC, ETEC and EIEC pathotypes. In detail, the following genes were detected: For EPEC, the eae, responsible for the production of the adhesin intimin; for EAEC, the aat A, encoding for a protein related to an ATP-binding cassette transport system; for STEC, the st 1 and st $x 2$, related to the production of the st $x 1$ and st $x 2$ toxins respectively; for ETEC, the ltA and stA, related to LT and ST toxins production; for EIEC, the ipa $\mathrm{H}$, associated with the invasion plasmid antigen $\mathrm{H}$ [34]. Primer sequences and amplicon sizes are described in Table 3. Template DNA for PCR reactions was produced by dissolving E. coli colony, cultivated on Tryptic Soy agar, in $20 \mu \mathrm{L}$ of DNAasi free water. The PCR mixture was performed in a final volume of $25 \mu \mathrm{L}$, consisting of $24 \mu \mathrm{L}$ of DreamTaq master mix 2X (Thermo Fisher Scientific, Rodano, Italy), $0.5 \mu \mathrm{L}$ of each genus primer, and $1.0 \mu \mathrm{L}$ of DNA template, previously obtained. The thermo cycle conditions were: 40 cycles of $95{ }^{\circ} \mathrm{C} 5 \mathrm{~min}, 95^{\circ} \mathrm{C} 40 \mathrm{~s}, 58^{\circ} \mathrm{C} 1 \mathrm{~min}, 72{ }^{\circ} \mathrm{C} 2 \mathrm{~min}$. PCR products were electrophoresed in $1.5 \%$ agarose gels gel containing Gel Red Nucleic Acid stain (Biotium, Fremont, USA) in 0.5 TBE ( $25 \mathrm{mM}$ Tris-borate, $0.5 \mathrm{mM}$ EDTA), and photographed under UV light (Axygen, Gel Documentation System). Amplicon sizes from each DEC sample were compared to those in the control strains to compose a genotype for each representative DEC group member. 
Table 3. Virulence factor primer sequences and amplicon sizes used in this study.

\begin{tabular}{|c|c|c|}
\hline Target Genes & Primer Sequences $\left(5^{\prime}-3^{\prime}\right)$ & Amplicons' Size (bp) \\
\hline st $x 1$ & $\begin{array}{c}\text { ATAAATCGCCATTCGTTGACTAC } \\
\text { AGAACGCCCACTGAGATCATC }\end{array}$ & 188 \\
\hline st $x 2$ & $\begin{array}{l}\text { GGCACTGTCTGAAACTGCTCC } \\
\text { TCGCCAGTTATCTGACATTCTG }\end{array}$ & 255 \\
\hline eae & $\begin{array}{l}\text { GACCCGGCACAAGCATAAGC } \\
\text { CCACCTGCAGCAACAAGAGG }\end{array}$ & 384 \\
\hline aat $A$ & $\begin{array}{l}\text { CTGGCGAAAGACTGTATCAT } \\
\text { CAATGTATAGAAATCCGCTGTT }\end{array}$ & 630 \\
\hline$i p a H$ & $\begin{array}{l}\text { CTCGGCACGTTTTAATAGTCTGG } \\
\text { GTGGAGAGCTGAAGTTTCTCTGC }\end{array}$ & 917 \\
\hline lt $A$ & $\begin{array}{l}\text { GGCGACAGATTATACCGTGC } \\
\text { CGGTCTCTATATTCCCTGTT }\end{array}$ & 450 \\
\hline$s t A$ & $\begin{array}{l}\text { ATTTTTMTTTCTGTATTRTCTT } \\
\text { CACCCGGTACARGCAGGATT }\end{array}$ & 190 \\
\hline
\end{tabular}

\subsection{Pulsed-Field Gel Electrophoresis (PFGE)}

The macro-restriction fragment separation by PFGE was performed using the 24-h PulseNet standardized PFGE protocol for E. coli non-O157:H7 [60]. Digestion was carried out with $50 \mathrm{U}$ of $\mathrm{XbaI}$ restriction enzyme (Thermo Fisher Scientific, Rodano, Italy) for $2 \mathrm{~h}$ at $37^{\circ} \mathrm{C}$, after pre-digestion in buffer for $5-10 \mathrm{~min}$ at $37^{\circ} \mathrm{C}$. DNA fragments were resolved in $1 \%$ agarose gel in $0.5 \mathrm{X}$ TBE electrophoresis buffer at $14{ }^{\circ} \mathrm{C}$, using the CHEF-DR III system (Bio-Rad Laboratories, Hercules, CA, USA). The runtime was $20 \mathrm{~h}$, with a constant voltage of $6 \mathrm{~V} / \mathrm{cm}$, using a linear pulse ramp of 6.76-35.58 s. PFGE images of gels were captured using Gel Documentation System (Axygen Scientific, Torino, Italy).

\subsection{Data Analyses}

The TIFF images obtained by PFGE were analyzed with a temporary BioNumerics evaluation license from Applied Maths (version 8.0 software package, Applied Maths, Sint-Martens-Latem, Belgium) from which we received permission to publish. The relatedness among the patterns was estimated by the proportions of shared bands, after applying the Dice coefficient. The UPGMA method was used to generate dendrograms with $1.5 \%$ tolerance values. The analysis of the patterns was confirmed visually.

Data obtained from antibiotic resistance between E. coli strains isolated from bovine and poultry animals were subjected to principal component analysis (PCA), using XLSTAT (2016), in order to achieve higher data compression efficiency.

\section{Conclusions}

In the present study, the high incidence of observed resistance against the most common antibiotics used in both human and veterinary practices, poses concern about the antibiotic resistance within the E. coli species. The proportion and the diversity of multidrugresistant phenotypes among E. coli isolates, even within the same pathogenic lineage, confirm a high probability of horizontal gene transfer. However, the usefulness of colistin, a last-resort antibiotic for the treatment of resistant gram-negative bacterial infections, was not compromised in this study. The observed high genetic diversity, highlighted by the unique pattern pulso-types obtained, confirms the independent origin of the strains, and the large genomic diversity within E. coli species. Further studies for DEC strains characterization are required in order to in-depth investigate the heterogeneous nature of EPEC strains. Furthermore, continuous surveillance to understand the role of nonpathogenic transmissible clones is desirable in order to recognize new patterns of virulence and identify the risk factors associated with the antibiotic resistance spread 
Supplementary Materials: The following are available online at https:/ / www.mdpi.com/2079-638 2/10/1/28/s1. Table S1. Origin and antibiotic resistance profiles of E. coli strains.

Author Contributions: Conceptualization, F.A. and C.C.; methodology, A.S., N.R., and A.P.; software, A.S. and N.R.; validation, C.L.R., G.C. and M.L.; investigation, A.S. and A.M.; resources, F.A. and G.C.; data curation, C.C., A.P., G.C.; writing—original draft preparation, N.R., A.S.; writing—review and editing, C.C., C.L.R.; supervision, C.C., M.L.; funding acquisition, F.A. All authors have read and agreed to the published version of the manuscript.

Funding: This study was conducted during a five-year period started with the projet "RC IZSSI 12/15, Studio sulla correlazione tra le principali malattie aziendali e il benessere animale la biosicurezza e il management nelle aziende di bovine da latte" (Scientific Responsible: G.C., Giuseppe Cascone) followed by the project "RC IZSSI 10/15, Analisi delle relazioni tra i componenti della filiera avicola siciliana quale strumento di gestione delle emergenze epidemiche" (Scientific Responsible: A.F., Francesco Antoci) at the Istituto Zooprofilattico Sperimentale della Sicilia "A. Mirri" (Palermo, Italy) in Ragusa.

Institutional Review Board Statement: Not applicable.

Informed Consent Statement: Not applicable.

Acknowledgments: This study was conducted within a Ph.D. research program in Agricultural, Food and Environmental Science (XXXIII cycle) conducted by Alessandro Stamilla, who received a grant by University of Catania at the Dipartimento di Agricoltura, Alimentazione e Ambiente (Scientific Tutors: M.L. Massimiliano Lanza and C.C. Cinzia Caggia). The authors thank Applied Maths for the temporary BioNumerics evaluation license and for the permission to publish data on PFGE images analysis. The authors thank Sabrina Sallemi for the collaboration and the precious help.

Conflicts of Interest: The authors declare no conflict of interest.

\section{References}

1. Croxen, M.A.; Law, R.J.; Scholz, R.; Keeney, K.M.; Wlodarska, M.; Finlay, B.B. Recent advances in understanding enteric pathogenic Escherichia coli. Clin. Microbiol. Rev. 2013, 26, 822-880. [CrossRef] [PubMed]

2. Guillaume Dalmasso, J.D. Escherichia coli: The Good, the Bad and the Ugly. Clin. Microbiol. 2015, 4, 2-4. [CrossRef]

3. Anderson, M.A.; Whitlock, J.E.; Harwood, V.J. Diversity and distribution of Escherichia coli genotypes and antibiotic resistance phenotypes in feces of humans, cattle, and horses. Appl. Environ. Microbiol. 2006, 72, 6914-6922. [CrossRef] [PubMed]

4. Moeller, A.H.; Suzuki, T.A.; Phifer-Rixey, M.; Nachman, M.W. Transmission modes of the mammalian gut microbiota. Science 2018, 362, 453-457. [CrossRef] [PubMed]

5. Loayza, F.; Graham, J.P.; Trueb, G. Factors obscuring the role of E. coli from domestic animals in the global antimicrobial resistance crisis: An evidence-based review. Int. J. Environ. Res. Public Health 2020, 17, 3061. [CrossRef] [PubMed]

6. Escribano-Vazquez, U.; Verstraeten, S.; Martin, R.; Chain, F.; Langella, P.; Thomas, M.; Cherbuy, C. The commensal Escherichia coli CEC15 reinforces intestinal defences in gnotobiotic mice and is protective in a chronic colitis mouse model. Sci. Rep. 2019, 7, 11431. [CrossRef]

7. Nataro, J.P.; Kaper, J.B. Diarrheagenic Escherichia coli. Clin. Microbiol. Rev. 1998, 11, 142-201. [CrossRef]

8. Hauser, E.; Mellmann, A.; Semmler, T.; Stoeber, H.; Wieler, L.H.; Karch, H.; Kuebler, N.; Fruth, A.; Harmsen, D.; Weniger, T.; et al. Phylogenetic and molecular analysis of food-borne shiga toxin-producing Escherichia coli. Appl. Environ. Microbiol. 2013, 79, 2731-2740. [CrossRef]

9. Poirel, L.; Madec, J.; Lupo, A.; Schink, A.; Kieffer, N.; Nordmann, P.; Schwarz, S. Antimicrobial resistance in Escherichia coli. Microbiol. Spectr. 2018, 6. [CrossRef]

10. The European Union One Health Zoonoses Report. European Food Safety Authority and European Centre for Disease Prevention and Control. 2019. Available online: https:/ / doi.org/10.2903/j.efsa.2019.5926 (accessed on 18 September 2020).

11. Matthijs, M.G.; Ariaans, M.P.; Dwars, R.M.; van Eck, J.H.; Bouma, A.; Stegeman, A.; Vervelde, L. Course of infection and immune responses in the respiratory tract of IBV infected broilers after superinfection with E. coli. Vet. Immunol. Immunopathol. 2009, 127, 77-84. [CrossRef]

12. Matter, L.; Barbieri, N.L.; Nordhoff, M.; Ewers, C.; Horn, F. Avian pathogenic Escherichia coli MT78 invades chicken fibroblast. Vet. Microbiol. 2011, 148, 51-59. [CrossRef] [PubMed]

13. De Carli, S.; Ikuta, N.; Lehmann, F.K.; da Silveira, V.P.; de Melo Pedrebon, G.; Fonseca, A.S.; Lunge, V.R. Virulence gene content in Escherichia coli isolates from poultry flocks with clinical signs of colibacillosis in Brazil. Poult. Sci. 2015, 94, 2635-2640. [CrossRef] [PubMed]

14. Luppi, A. Swine enteric colibacillosis: Diagnosis, therapy and antimicrobial resistance. Porc. Health Manag. 2017, 3, 16. [CrossRef] [PubMed] 
15. Sgariglia, E.; Aconiti Mandolini, N.; Napoleoni, M.; Medici, L.; Fraticelli, R.; Conquista, M.; Gianfelici, P.; Staffolani, M.; Fisichella, S.; Capuccella, M.; et al. Antibiotic resistance pattern and virulence genes in avian pathogenic Escherichia coli (APEC) from different breeding systems. Vet. Ital. 2019, 55, 27-33. [CrossRef]

16. McEwen, S.A. Antibiotic use in animal agriculture: What have we learned and where are we going? Anim. Biotechnol. 2006, 17, 239-250. [CrossRef] [PubMed]

17. Ungemach, F.R.; Muller-Bahrdt, D.; Abraham, G. Guidelines for prudent use of antimicrobials and their implications on antibiotic usage in veterinary medicine. Int. J. Med. Microbiol. 2006, 296, 33. [CrossRef] [PubMed]

18. Shaheen, B.W.; Boothe, D.M.; Oyarzabal, O.A.; Smaha, T. Antimicrobial resistance profiles and clonal relatedness of canine and feline Escherichia coli pathogens expressing multidrug resistance in the United States. J. Vet. Intern. Med. 2010, 24, 323-330. [CrossRef]

19. Lukjancenko, O.; Wassenaar, T.M.; Ussery, D.W. Comparison of 61 sequenced Escherichia coli genomes. Microb. Ecol. 2010, 60, 708-720. [CrossRef]

20. Ventola, C.L. The Antibiotic Resistance Crisis: Part 1-Causes and Threats. Pharm. Ther. 2015, 40, $277-283$.

21. Agga, G.E.; Cook, K.L.; Netthisinghe, A.M.P.; Gilfillen, R.A.; Woosley, P.B.; Sistani, K.R. Persistence of antibiotic resistance genes in beef cattle backgrounding environment over two years after cessation of operation. PLoS ONE 2019, 14, e0212510. [CrossRef]

22. Bacanli, M.; Başaran, N. Importance of antibiotic residues in animal food. Food Chem. Toxicol. 2019, 125, 462-466. [CrossRef] [PubMed]

23. Hedman, H.D.; Vasco, K.A.; Zhang, L. A Review of Antimicrobial Resistance in Poultry Farming within Low-Resource Settings. Animals 2020, 10, 1264. [CrossRef] [PubMed]

24. Kimera, I.Z.; Mshana, S.E.; Rweyemamu, M.M.; Mboera, L.E.G.; Matee, M.I.N. Antimicrobial use and resistance in food producing animals and the environment: An African perspective. Antimicrob. Resist. Infect. Control. 2020, 9, 37. [CrossRef] [PubMed]

25. Paitan, Y. Current trends in antimicrobial resistance of Escherichia coli. In Escherichia coli, a Versatile Pathogen. Current Topics in Microbiology and Immunology; Frankel, G., Ron, E., Eds.; Springer: Cham, Switzerland, 2018; Volume 416. [CrossRef]

26. Singer, R.S.; Reid-Smith, R.; Sischo, W.M. Stakeholder position paper: Epidemiological perspectives on antibiotic use in animals. Prev. Vet. Med. 2006, 24, 153-161. [CrossRef] [PubMed]

27. The European Committee on Antimicrobial Susceptibility Testing. The European Committee on Antimicrobial Susceptibility Testing Breakpoint Tables for Interpretation of MICs and Zone Diameters Version 10.0. Valid from 2020-01-01. Available online: http:/ / www.eucast.org/clinical_breakpoints (accessed on 18 September 2020).

28. Clinical and Laboratory Standards Institute. Performance Standards for Antimicrobial Disk Susceptibility Approved Standard-30th Edition; CLSI Document M100; Clinical and Laboratory Standards Institute: Wayne, PA, USA, 2018.

29. Stenske, A.K.; Bemis, D.A.; Gillespie, B.A.; Doris, M.S.; D’Souza, H.; Oliver, S.P.; Draughon, F.A.; Matteson, K.J.; Bartges, J.W. Comparison of clonal relatedness and antimicrobial susceptibility of fecal Escherichia coli from healthy dogs and their owners. Am. J. Vet. Res. 2009, 70, 1108-1116. [CrossRef] [PubMed]

30. Aarestrup, F.M.; Duran, C.O.; Burch, D.G.S. Antimicrobial resistance in swine production. Anim. Health Res. Rev. 2008, 9, 135-148. [CrossRef] [PubMed]

31. Aarestrup, F.M. Monitoring of Antimicrobial Resistance among Food Animals: Principles and Limitations. J. Vet. Med. 2004, 51, 8-9. [CrossRef]

32. Dziva, F.; Stevens, M.P. Colibacillosis in poultry: Unravelling the molecular basis of virulence of avian pathogenic Escherichia coli in their natural hosts. Avian Path. 2008, 37, 355-366. [CrossRef]

33. Olesen, B. Characterization of Four Escherichia coli Clonal Groups. Ph.D. Thesis, Faculty of Health and Medical Sciences, University of Copenhagen, Copenhagen, Denmark, August 2017. [CrossRef]

34. Ori, E.L.; Takagi, E.H.; Andrade, T.S.; Miguel, B.T.; Cergole-Novella, M.C.; Guth, B.E.C.; Hernandes, R.T.; Dias, R.C.B.; Pinheiro, S.R.S.; Camargo, C.H.; et al. Diarrhoeagenic Escherichia coli and Escherichia albertii in Brazil: Pathotypes and serotypes over a 6-year period of surveillance. Epidemiol. Infect. 2018, 147, 1-9. [CrossRef]

35. Obeng, A.S.; Rickard, H.; Ndi, O.; Sexton, M.; Barton, M. Antibiotic resistance, phylogenetic grouping and virulence potential of Escherichia coli isolated from the faeces of intensively farmed and free range poultry. Vet. Microbiol. 2012, 154, 305-315. [CrossRef]

36. Saira, B.; Yasra, S.; Aamir, A.; Mashkoor, M.; Muhammad, A.S.; Ayesha, T. Multiple drug resistance patterns in various phylogenetic groups of Uropathogenic E. coli isolated from faisalabad region of Pakistan. Braz. J. Microbiol. 2011, 42, $1278-1283$.

37. Bukh, A.S.; Schonheyder, H.C.; Emmersen, J.M.; Sogaard, M.; Bastholm, S.; Roslev, P. Escherichia coli phylogenetic groups are associated with site of infection and level of antibiotic resistance in community-acquired bacteraemia: A 10 year population-based study in Denmark. J. Antimicrob. Chemother. 2009, 64, 163-168. [CrossRef] [PubMed]

38. Molina-López, J.; Aparicio-Ozores, G.; Ribas-Aparicio, R.M.; Gavilanes-Parra, S.; Chávez-Berrocal, M.E.; Nataro, J.P.; Kaper, J.B. Drug resistance, serotypes, and phylogenetic groups among uropathogenic Escherichia coli including O25-ST131 in Mexico City. J. Infect. Dev. Ctries. 2011, 5, 840-849. [CrossRef] [PubMed]

39. Sayah, R.S.; Kaneene, J.B.; Johnson, Y.; Miller, R. Patterns of antimicrobial resistance observed in Escherichia coli isolates obtained from domestic- and wild-animal fecal samples, human septage, and surface water. Appl. Environ. Microbiol. 2005, 71, 1394-1404. [CrossRef]

40. Kazemnia, A.; Ahmadi, M.; Dilmaghani, M. Antibiotic resistance pattern of different Escherichia coli phylogenetic groups isolated from human urinary tract infection and avian colibacillosis. Iran. Biomed. J. 2014, 18, 219-224. [CrossRef] 
41. Bonnet, R. Growing group of extended spectrum: The CTX-M enzymes. Antimicrob. Agent. Chemother. 2004, 48, 1-14. [CrossRef]

42. Mathers, A.J.; Peirano, G.; Pitout, J.D.D. The role of epidemic resistance plasmids and international high- risk clones in the spread of multidrug-resistant Enterobacteriaceae. Clin. Microbiol. Rev. 2015, 28, 565-591. [CrossRef]

43. Van den Bogaard, A.E.; London, N.; Driessen, C.; Stobberingh, E.E. Antibiotic resistance of faecal Escherichia coli in poultry, poultry farmers and poultry slaughterers. J. Antimicrob. Chemother. 2001, 47, 763-771. [CrossRef]

44. Johura, F.T.; Tasnim, J.; Barman, I. Colistin-resistant Escherichia coli carrying $m c r-1$ in food, water, hand rinse, and healthy human gut in Bangladesh. Gut Pathog. 2020, 12, 5. [CrossRef]

45. Matuschek, E.; Åhman, J.; Webster, C.; Kahlmeter, G. Antimicrobial susceptibility testing of colistin-Evaluation of seven commercial MIC products against standard broth microdilution for Escherichia coli, Klebsiella pneumoniae, Pseudomonas aeruginosa and Acinetobacter spp. Clin. Microbiol. Infect. 2018, 24, 865. [CrossRef]

46. The European Committee on Antimicrobial Susceptibility Testing. European Committee on Antimicrobial Susceptibility Testing Breakpoint Tables for Interpretation of MICs and Zone Diameters. 2017. Version 7.1 valid from 2017-03-10. Available online: http:/ / www.eucast.org (accessed on 30 December 2020).

47. Loose, M.; Naber, K.G.; Coates, A.; Wagenlehner, F.M.E.; Hu, Y. Effect of different media on the bactericidal activity of colistin and on the synergistic combination with azidothymidine against mcr-1-positive colistin-resistant Escherichia coli. Front. Microbiol. 2020, 11, 54. [CrossRef] [PubMed]

48. Baron, S.; Hadjadj, L.; Rolain, J.M.; Olaitan, A.O. Molecular mechanism of polymxin resistance: Knows and unknows. Int. J. Antimicrob. Agents 2016, 48, 583-591. [CrossRef] [PubMed]

49. Cannatelli, A.; D'Andrea, M.M.; Giani, T.; Di Pilato, V.; Arena, F.; Ambretti, S. In vivo emergence of colistin resistance in Klebsiella pneumoniae producing KPC-type carbapenemases mediated by insertional inactivating of the PhoQ/PhoP mgrB regulator. Antimicrob. Agents Chemother. 2016, 57, 5521-5526. [CrossRef] [PubMed]

50. Lui, Y.Y.; Wang, Y.; Walsh, T.R.; Yi, L.X.; Zhang, R.; Spencer, J. Emergence of plasmid-mediated colistin resistance mechanism mcr-1 in animals and human beings in China: A microbiological and molecular biological study. Lancet Infect. Dis. 2016, 16, 161-168. [CrossRef]

51. Russo, N.; Pino, A.; Toscano, A.; Cirelli, G.L.; Caggia, C.; Arioli, S.; Randazzo, C.L. Occurrence, diversity, and persistence of antibiotic resistant enterococci in full-scale constructed wetlands treating urban wastewater in Sicily. Bioresour. Technol. 2019, 274, 468-478. [CrossRef] [PubMed]

52. $\mathrm{Du}, \mathrm{Z}$. The prevalence of amphenicol resistance in Escherichia coli isolated from pigs in mainland China from 2000 to 2018 : A systematic review and meta-analysis. PLOS ONE 2020, 15, e0228388. [CrossRef]

53. Chapman, T.A.; Wu, X.Y.; Barchia, I.; Bettelheim, K.A.; Driesen, S.; Trott, D.; Wilson, M.; Chin, J.J. Comparison of virulence gene profiles of Escherichia coli strains isolated from healthy and diarrheic swine. Appl. Environ. Microbiol. 2006, 72, $4782-4795$. [CrossRef]

54. Cundon, C.; Carbonari, C.C.; Zolezzi, G.; Rivas, M.; Bentancor, A. Putative virulence factors and clonal relationship of O174 Shiga toxinproducing Escherichia coli isolated from human, food and animal sources. Vet. Microb. 2018, 215, 29-34. [CrossRef]

55. Milkman, R. Electrophoretic variation in Escherichia coli from natural sources. Science 1973, 182, 1024-1026. [CrossRef]

56. Milkman, R. Recombination and population structure in Escherichia coli. Genetics 1997, 146, 745-750.

57. Peerayeh, S.N.; Navidinia, M.; Fallah, F.; Bakhshi, B.; Alebouyeh, M. Evaluation of clonal relatedness among different sources of E. coli isolates in Iranian children with urinary tract infection (UTI) and age-matched healthy people. Biomed. Res. 2019, 30. [CrossRef]

58. Klein, G.; Bulte, M. Antibiotic susceptibility pattern of Escherichia coli strains with verocytotoxic E. coli-associated virulence factors from food and animal species. Food Microbiol. 2003, 20, 27-33. [CrossRef]

59. Technical Committee ISO/TC 212: Clinical Laboratory Testing and In Vitro Diagnostic Test Systems. ISO 20776-1:2019Susceptibility Testing of Infectious Agents and Evaluation of Performance of Antimicrobial Susceptibility Test Devices-Part 1: Broth Micro-Dilution Reference Method for Testing the In Vitro Activity of Antimicrobial Agents Against Rapidly Growing Aerobic Bacteria Involved in Infectious Diseases. Available online: https:/ / www.iso.org/standard/70464.html (accessed on 30 December 2020).

60. Centers for Disease Control and Prevention, CDC: PulseNet. PNL04 Standard Operating Procedure for PulseNet PFGECDC, July 2017, Atlanta, USA. Available online: https://www.cdc.gov/pulsenet/pdf/listeria-pfge-protocol-508c.pdf (accessed on 18 September 2020). 